\title{
Inhibitive Action of Polymeric Surfactants on the Corrosion of C-Steel In 0.5
} Mhcl

\author{
A.A.Abdel-Fattah, H.E.Megahed, A.A.Ali and S.M.Syam \\ Chemistry Dept., Faculty of Science, Benha Univ., Benha, Egypt \\ E-Mail: ashraf.abdelfattah@fsc.bu.edu.eg
}

\begin{abstract}
The inhibitive effect of polymeric surfactants on the corrosion of carbon steel in $0.5 \mathrm{M} \mathrm{HCl}$ has been investigated by weight loss and polarization techniques. Potentiodynamic polarization measurements showed that these compounds are mixed type inhibitors. The adsorption of these inhibitors on carbon steel surface obeys Langmuir adsorption isotherm. The effect of temperature on the corrosion behavior of carbon steel in hydrochloric acid in presence of the most effective concentrations of the inhibitors was studied in temperature range $\left(25-70^{\circ} \mathrm{C}\right)$. The associated activation energy of carbon steel corrosion as well as energy of adsorption of studied compounds has been determined.
\end{abstract}

Keywords: Polarization techniques, Carbon steel corrosion .

\section{Introduction}

Carbon steel is one of the most important alloys used in several fields of industry. Carbon steel and similar alloys can be exposed to corrosion when exposed to aggressive environmental conditions, especially in environment containing $\mathrm{Cl}^{-}$ions. $\mathrm{As} \mathrm{Cl}^{-}$ ion was an active one, it may force oxide formation on metal surface by adsorbing as alternative on metal surface. This increases the corrosion rate of metal. Acid solution was widely used in industrial acid cleaning, acid descaling, acid picking and oil-well acidizing [1]. In order to reduce the corrosion rate of metals, several techniques have been applied. The use of inhibitors was one of the most practical methods for protection against corrosion in acidic media. Inhibitors which reduce corrosion on metallic materials can be divided into four kinds: i. inorganic inhibitors, ii. organic inhibitors, iii. surfactant inhibitors, and (iv) mixed material inhibitors. Surfactant inhibitors have many advantages such as, for example, high inhibition efficiency, low price, low toxicity, and easy production [2-11]. The application of surfactants as corrosion inhibitors has been extensively studied, and adsorption of the surfactant on the metal surface was found to be responsible for the corrosion inhibition of the metal surface. Most acid inhibitors were organic compounds containing phosphorus, nitrogen, sulfur and/or oxygen atoms [12]. The corrosion inhibition of a metal may involve either physisorption or chemisorption of the inhibitor on the metal surface. Electrostatic attraction between the charged hydrophilic groups and the charged active centers on the metal surface leads to physicosorption. Some authors showed that most organic inhibitors were adsorbed on the metal surface by displacing water molecules from the surface and forming a compact barrier film [13]. The growing interest in using surface active polymer "polymeric surfactants" instead of the traditional surfactant molecules can be said to emanate from having a very strong driving force to go to the interfaces and the tendency to collect at these interfaces is not as dependent on physical variables as for normal, low molecular weight surfactants. This means that the polymeric surfactants are effective at low concentrations [14]. The choice of optimal inhibitor should be based on three considerations: i. it should have a convenient synthesis from inexpensive raw materials, ii. the presence of phosphorus, nitrogen, oxygen, sulfur atom and multiple bonds in the inhibitor molecule was required for its efficiency and iii. its toxicity toward the environment must be negligible [15].

\section{Materials and methods \\ 2.1 Specimens}

Samples used in this study were C-steel with a chemical composition (in wt\%) C (0.27), Mn (0.85), $\mathrm{P}$ (0.035), S (0.035), Si (0.15) and Fe (98.66). They were cut as regular edged coupons with dimension $1.7 \times 1.8 \times 0.6 \mathrm{~cm}$.

\subsection{Solutions}

The aggressive solution, $0.5 \mathrm{M} \mathrm{HCl}$ was prepared by dilution of analytical grade $37 \% \mathrm{HCl}$ with distilled water.

\subsection{Inhibitors}

Two prepared nonionic polymeric surfactants [16] were used having the following structure:

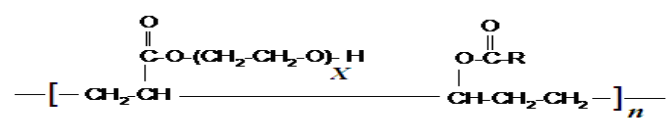

$$
\mathrm{R}=\mathrm{C}_{11} \mathrm{H}_{23}
$$

Where $\mathrm{x}$ is number of ethylene glycol groups of PEG with Mwts= 600 and 2000 .

\subsection{Weight loss measurements}

In the weight loss experiments, carbon steel coupons were polished by different grades of emery papers (from 100 up to 1200), respectively, degreased with acetone, washed with distilled water and finally dried using two filter papers. The described treatment was carried out immediately 
before each measurement. Coupons were suspended in $250 \mathrm{ml}$ glass vessel containing $100 \mathrm{ml}$ of test solutions with the aid of glass rods and hooks maintained at $25^{\circ} \mathrm{C}$ in a thermostated bath for $3 \mathrm{hrs}$. The weight loss was taken to be the difference between the weight at a given time and the original weight of the coupons. The measurements were carried out for the uninhibited solution (blank) and in inhibited solution. The inhibition efficiency (\%I.E) of polymeric surfactants was evaluated using the following equation [17]:

$\% \mathrm{I} . \mathrm{E}=\left[1-\left(\mathrm{CR} / \mathrm{CR}^{\mathrm{O}}\right)\right] \times 100$

where $\mathrm{CR}$ is corrosion rate for carbon steel in blank $\mathrm{HCl}$ and $\mathrm{CR}^{\mathrm{O}}$ is corrosion rate of carbon steel in presence of inhibitors at the same temperature. The corrosion rate of carbon steel in different concentrations of the acid, inhibitors (polymeric surfactants) have been determined for 3 hrs. using the expression:

Corrosion rate $(\mathrm{CR})=\Delta \mathrm{W} / \mathrm{At}$

where $\Delta \mathrm{W}$ is the weight loss (mg) (obtained as difference between initial weight and weight at a given time $\mathrm{t}, \mathrm{hr}$ ) and $\mathrm{A}$ is the area of the specimen $\left(\mathrm{cm}^{2}\right)$.

\section{5 Polarization measurements}

Platinum electrode and a saturated calomel (SCE) electrode were used as auxiliary and reference electrodes, respectively. The samples of steel is of surface area $1 \mathrm{~cm}^{2}$, were first immersed into the solution for 10 minutes to establish a steady state open circuit potential. The effect of inhibitor on steel corrosion was determined by measuring corrosion rate in different concentration of polymeric surfactants. For the evaluation of inhibitor concentration effects on inhibition efficiency (the protection of corrosion) experiments were carried out in $0.5 \mathrm{MHCl}$ in the absence and presence of various concentrations of inhibitors. The cell was left open to air at room temperature $\left(25^{\circ} \mathrm{C}\right)$. All potential values were reported in millivolt (SCE). The electrochemical polarization was also done after 10 min immersion in inhibited solution.

The effect of temperature on corrosion inhibition of polymeric surfactants was, also investigated at five different temperatures.

\section{Results and discussion}

\section{1 weight loss measurement}

\subsubsection{Weight loss measurements for free acid}

The corrosion rate of carbon steel in different concentrations of hydrochloric acid solutions (from $0.5 \mathrm{M}$ to $3.0 \mathrm{M}$ ) were determined chemically by weight loss measurements at $298 \mathrm{~K}$. Fig (1) shows the variation of corrosion rate of carbon steel with hydrochloric acid concentration at $298 \mathrm{~K}$. It is obvious from Table (1) that, the corrosion rates of carbon steel increase with increasing the concentration of hydrochloric acid. This increase in corrosion rates can be attributed to increased aggressiveness of solutions with increase in acid concentration. For the corrosion of carbon steel in hydrochloric acid, the anodic (metal dissolution) and cathodic (hydrogen evolution) half reactions are:

$$
\begin{aligned}
& \mathrm{Fe} \rightarrow \mathrm{Fe}^{+2}+2 \mathrm{e}^{-} \\
& 2 \mathrm{H}^{+}+2 \mathrm{e}^{-} \rightarrow \mathrm{H}_{2}
\end{aligned}
$$

Table (1) Corrosion rates obtained from weight loss measurements at different concentrations $\mathrm{HCl}$ for $3 \mathrm{hrs}$.

\begin{tabular}{lll}
\hline $\mathbf{C , M}$ & wtloss $(\mathbf{m g})$ & $\mathbf{C R}\left(\mathbf{m g . c m} \mathbf{c m}^{-\mathbf{2}} \mathbf{h} \mathbf{-}^{-1}\right)$ \\
\hline 0.5 & 1.5 & 0.076 \\
1 & 1.6 & 0.081 \\
2 & 1.8 & 0.091 \\
3 & 2.0 & 0.101 \\
\hline
\end{tabular}

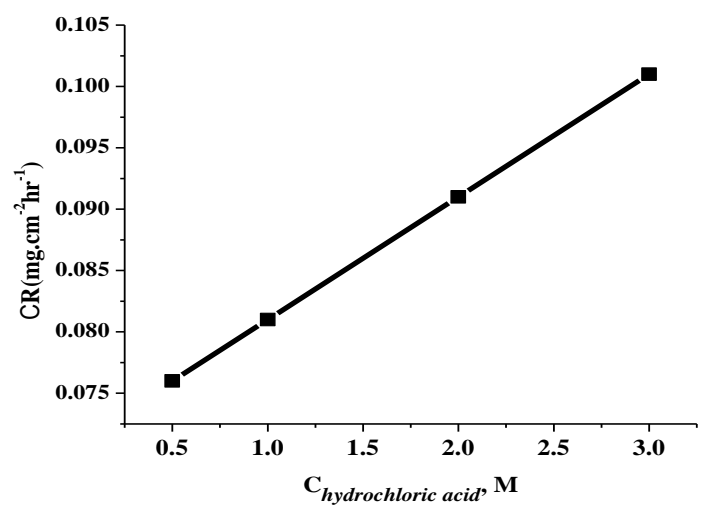

Fig (1) Variation of corrosion rate of carbon steel with hydrochloric acid concentrations at 298K.

\subsubsection{Weight loss measurements for polymeric surfactants}

Fig (2) shows the variation of corrosion rate of carbon steel in $0.5 \mathrm{M}$ hydrochloric acid solution in the presence of various concentrations of synthesized polymeric surfactants. It is obvious that in all cases studied, the corrosion rates decrease with increasing the concentration of the polymeric 
surfactants. The degree of inhibition depends polymeric surfactants upon the nature and the concentration of the
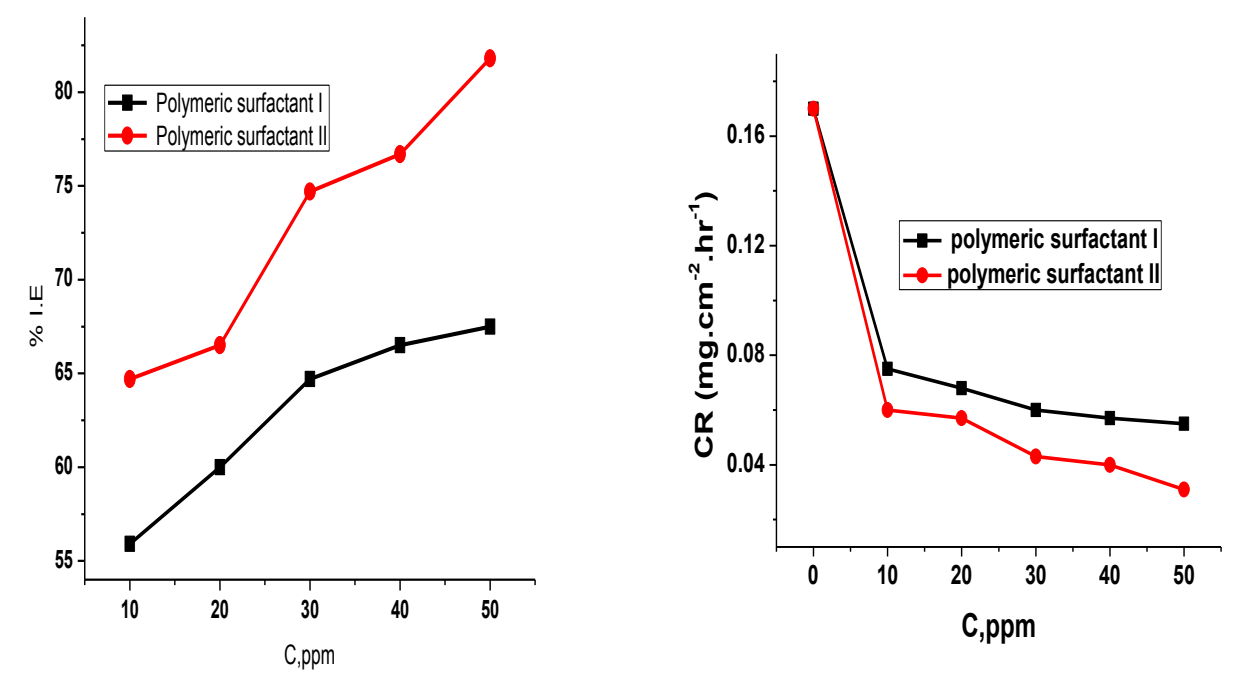

Fig (2) Relation between concentration of polymeric surfactants versus their corrosion rates and inhibition efficiency for $3 \mathrm{hrs}$.

The data in Table (2) reveals that the inhibition efficiency for all the compounds increases with increase in concentration. The inhibition efficiency $\%$ I.E of these compounds increases in the order:polymeric surfactant II > polymeric surfactant I. It is clear that these compounds are good corrosion inhibitors for carbon steel in hydrochloric acid solution. These polymeric surfactants inhibit the acid dissolution of carbon steel by adsorption at the Fe/acid solution interface. The adsorption process takes place via ion pair and ion exchange mechanism by their ethylene oxide groups [18]. Inhibition of the polymeric surfactants can be explained by a substitution adsorption of the surfactants according to equation (5).

Polymer(aq) $+\mathrm{xH}_{2} \mathrm{O}(\mathrm{ads}) \rightarrow$ Polymer(ads) + $\mathrm{xH}_{2} \mathrm{O}(\mathrm{aq})$

Table (2) Corrosion rates obtained from weight loss measurements with different concentrations of polymeric surfactant I, II (PEG MWT= 600, 2000) for $3 \mathrm{hrs}$.

\begin{tabular}{lcccc}
\hline C,ppm & \multicolumn{2}{c}{ Polymeric surfactant I } & \multicolumn{2}{c}{ Polymeric surfactant II } \\
\hline 0 & CR(mg.cm-2.hr-1) & \% I.E & CR(mg.cm-2.hr-1) & \% I.E \\
\cline { 2 - 5 } 10 & 0.170 & -------- & -170 & 64.7 \\
20 & 0.075 & 55.9 & .060. & 66.5 \\
30 & 0.068 & 60.0 & 0.057 & 74.7 \\
40 & 0.060 & 64.7 & 0.043 & 76.5 \\
50 & 0.057 & 66.5 & 0.040 & 81.8 \\
\hline
\end{tabular}

\section{2 polarization measurement}

Fig (3) shows the anodic and cathodic polarization curves of $\mathrm{C}$-steel in $0.5 \mathrm{M} \mathrm{HCl}$ solutions in presence and absence of polymeric surfactants. Used compounds, approximately, change the profile of anodic and cathodic curves, but affect more on the cathodic area.

This indicates that, they merely block the reaction sites of carbon steel surface without affecting the anodic and cathodic reaction mechanisms. With increasing the inhibitor concentration, no obvious trend is observed in the shift of $E_{\text {corr }}$ values, suggesting that these compounds behave as mixed inhibitors.

Tables $(3,4)$ show the electrochemical corrosion parameters (corrosion potential $\left(\mathrm{E}_{\mathrm{corr}}\right)$, cathodic and anodic tafel slopes $\left(\beta_{\mathbf{c}}, \beta_{\mathbf{a}}\right)$ and corrosion current density $\left(i_{\text {corr }}\right)$ obtained by extrapolation of Tafel lines), of carbon steel in $0.5 \mathrm{M} \mathrm{HCl}$ devoid of and 
containing different concentrations of polymeric surfactants. The inhibition efficiency (\% I.E) and surface coverage $(\theta)$ are also calculated using the following equations $[19,20]$

$$
\% \text { I.E }=\left[\left(\mathbf{i}_{\text {corr }}^{\mathbf{o}}-\mathrm{i}_{\text {corr }}\right) / \mathrm{i}_{\text {corr }}^{\mathbf{o}}\right] \times 100
$$$$
\theta=1-\left(\mathrm{i}_{\text {corr }} / \mathrm{i}_{\text {corr }}^{\mathbf{0}}\right)
$$

where $\mathrm{i}_{\text {corr }}^{\mathbf{0}}$ and $\mathrm{i}_{\text {corr }}$ are corrosion current densities of uninhibited and inhibited, respectively.

The data imply that the polymeric surfactant II has higher corrosion inhibition than polymeric surfactant I and indicating that the corrosion inhibition of these polymer increases with increasing their molecular weights. This due to the increase in the number of ethylene oxide groups [(-CH2OCH2)n] with increasing the molecular weight of polymer. This causes an increase in the bulkiness of the groups attached to the adsorption center [18] and hence reduces the rate of corrosion.

\subsubsection{Adsorption isotherm}

The mechanism of corrosion inhibition may be explained on the basis of adsorption behavior.

The degrees of surface coverage $(\theta)$ for different inhibitor concentrations were evaluated by the weight-loss method using the following equations:

$\theta=\left(\mathrm{CR}^{0}-\mathrm{CR} / \mathrm{CR}^{0}\right)$

Attempts were made to fit these $\theta$ values to Langmuir adsorption isotherm, which has the form [21]:

$\mathrm{C} / \theta=1 / \mathrm{K}_{\mathrm{ads}}+\mathrm{C}$

where $\mathrm{K}_{\mathrm{ads}}$ is equilibrium constant of adsorption process. The plot of $\mathrm{C} / \theta$ as a function of polymeric surfactants concentration, $\mathrm{C}$ is the bulk concentration of the inhibitor, is shown in Fig (4). From the plot, straight lines were obtained with $\mathrm{R}^{2}>0.9$ for all polymeric surfactants used, indicating that the experimental data fit well into the Langmuir adsorption isotherm. The adsorption parameters from Langmuir adsorption isotherm are estimated and listed in Table (5).

It is evident that the values of $\mathrm{K}_{\mathrm{ads}}$ increase with increasing the polymer molecular weight (i.e. polymeric surfactant II > polymeric surfactant I. This clearly indicates that the strength of electrical interactions between adsorbing molecules and the surface increases in the same order as mentioned previously [22], thus increasing the inhibition efficiency.

The standard free energy of inhibitor adsorption $\Delta \mathrm{G}_{\text {ads }}^{0}$ on carbon steel surface can be evaluated using the following equation [23]:

(10)

$$
\log \mathrm{K}_{\mathrm{ads}}=\log (1 / 55.5)-\Delta \mathrm{G}_{\mathrm{ads}}^{0} / 2.303 \mathrm{RT}
$$

where the value 55.5 is the concentration of water in solution in $\mathrm{M}, \mathrm{R}$ is the universal gas constant and $\mathrm{T}$ is absolute temperature. $\Delta \mathrm{G}_{\text {ads }}^{0}$ values are listed in Table (5) Negative values of $\Delta \mathrm{G}_{\text {ads }}^{0}$ are a characteristic feature of strong spontaneous adsorption for the studied polymers, which also reflect the high values of inhibition.
The negative $\Delta \mathrm{G}^{0}$ ads values are consistent with the spontaneity of the adsorption process and the stability of the adsorbed layer on carbon steel surface [24]. In general, the standard free energy values of $20 \mathrm{~kJ} \mathrm{~mol}^{-1}$ or less negative are associated with an electrostatic interaction between charged molecules and charged metal surface, resulting in physisorption and those of $-40 \mathrm{~kJ} \mathrm{~mol}^{-1}$ or more negative values involve charge sharing or transfer from the inhibitor molecules to the metal surface to form a coordinate covalent bond, resulting in chemisorption [24]. The $\Delta \mathrm{G}_{\text {ads }}^{0}$ values obtained for the studied polymeric surfactants on the metal surface indicates physical adsorption.

\subsubsection{Effect of temperature}

The influence of solution temperature $\left(25-70^{\circ} \mathrm{C}\right)$ on the anodic and cathodic polarization characteristics of carbon steel in $0.5 \mathrm{M} \mathrm{HCl}$ solution without and with specific concentration of used polymeric surfactants was measured. The obtained results are depicted in fig (5). The electrochemical parameters associated with these results are summarized in Tables $(6,7$, and 8$)$.

From these tables, one can see that the increase in solution temperature enhances corrosion current densities and corrosion rate of carbon steel without and with polymeric surfactants increase with increasing the solution temperature.

From these tables, one can see that the increase in solution temperature enhances corrosion current densities and corrosion rate of carbon steel without and with polymeric surfactants increase with increasing the solution temperature.

\subsubsection{Thermodynamic parameters}

In acidic solution, the logarithm of corrosion rate is a linear function of $1 / \mathrm{T}$ (Arhenius type equation) with a slope $-\mathrm{E}_{\mathrm{a}} * / 2.303 \mathrm{R} .[25]$

$$
\mathrm{I}_{\text {corr }}=\mathrm{k} \exp \left(-\mathrm{E}_{\mathrm{a}} * / \mathrm{RT}\right)
$$

where $\mathrm{I}_{\text {corr }}$ is the corrosion current density, $\mathrm{E}_{\mathrm{a}} *$ is the apparent activation energy, $\mathrm{T}$ is the absolute temperature, $\mathrm{k}$ is the Arrhenius pre-exponential constant and $\mathrm{R}$ is the universal gas constant.

Typical plots are shown in fig (6) and calculated activation energies for the blank solution and in presence of specific concentrations of polymeric surfactants used are given in Table (9).

Plots of $\log \left(\mathrm{I}_{\text {corr }} / \mathrm{T}\right)$ vs. 1/T for carbon steel in $0.5 \mathrm{M} \mathrm{HCl}$ at the specific concentrations of used polymeric surfactants are shown in Fig (7). As shown in this fig, straight lines with slopes of $\left(-\Delta H^{*} /\right.$ $2.303 \mathrm{R})$ and intercept of $\left(\log \mathrm{R} / \mathrm{Nh}+\Delta \mathrm{S}^{*} / 2.303\right.$ $\mathrm{R})$ were obtained according to the transition state equation [25]:

(12)

Rate $=\mathrm{RT} / \mathrm{Nh} \exp \left(\Delta \mathrm{S}^{*} / \mathrm{R}\right) \exp \left(-\Delta \mathrm{H}^{*} / \mathrm{RT}\right)$

Where $\mathrm{h}$ is the Planck's constant, $\mathrm{N}$ is the Avogadro's number, $\Delta \mathrm{H}^{*}$ is the activation enthalpy and $\Delta \mathrm{S}^{*}$ is the activation entropy. 
The calculated values of apparent activation energy $E_{a}{ }^{*}$, activation enthalpies, $\Delta H^{*}$ and the activation entropies, $\Delta \mathrm{S}^{*}$ are given in Table (9). The increase in the activation enthalpy $\left(\Delta \mathrm{H}^{*}\right)$ in the presence of the inhibitors implies that the addition of the inhibitors to the acid solution increases the height of energy barrier of the corrosion reaction to an extent depends on the type and concentration of the present inhibitor [26]. The entropy of activation $\left(\Delta S^{*}\right)$ in the blank and inhibited solution is large and negative indicating that the activated complex represent association rather than dissociation step [26].

The order of decreasing inhibition efficiency of the investigated compounds as detected from the increase in $\mathrm{E}_{\mathrm{a}}{ }^{*}$ and $\Delta \mathrm{H}^{*}$ values and decrease in $\Delta \mathrm{S}^{*}$ values, is as follows:

polymeric surfactant II > polymeric surfactant I
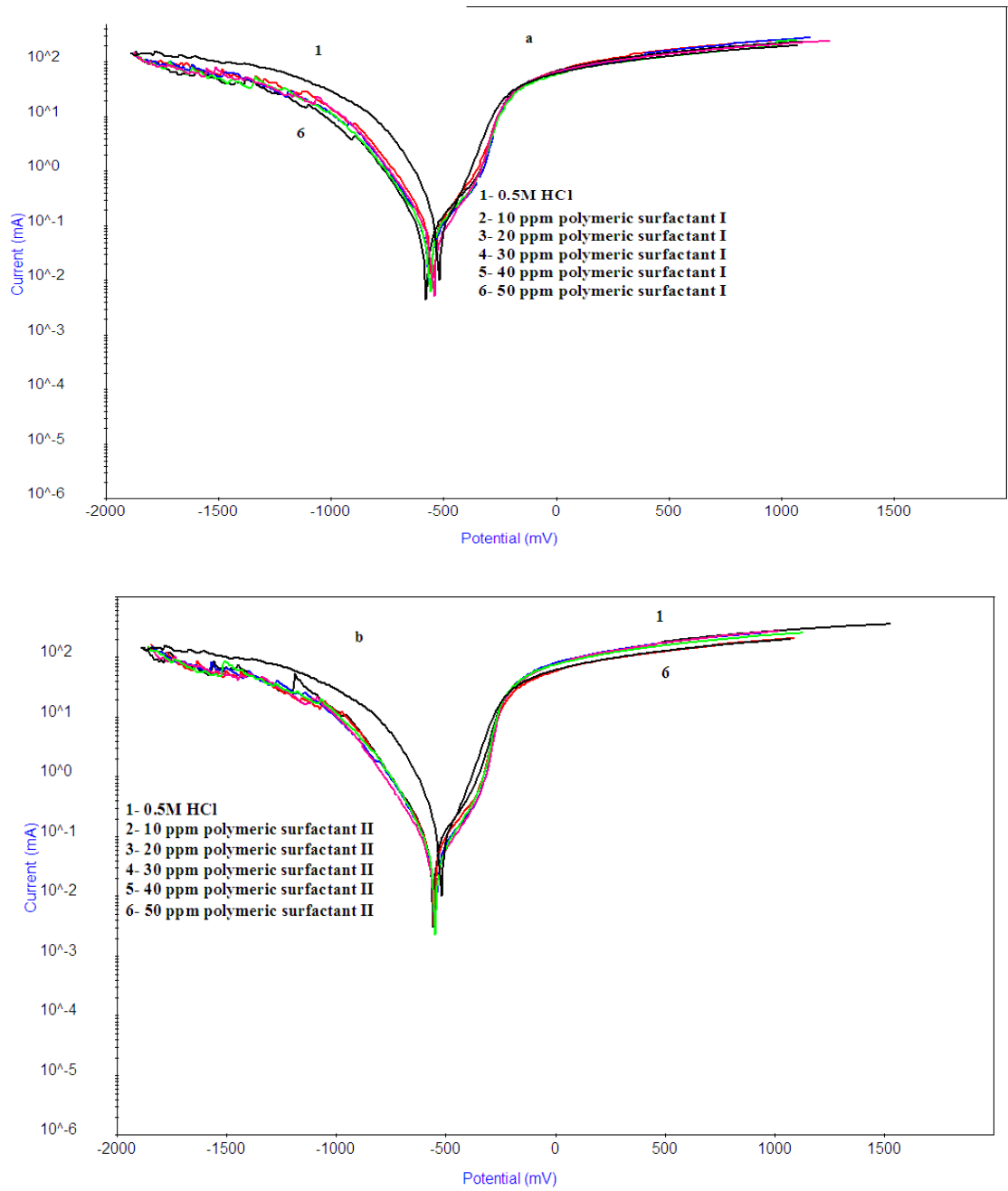

Fig (3) Electrochemical polarization curves of carbon steel in $0.5 \mathrm{M} \mathrm{HCl}$ without and with (a) different concentrations of polymeric surfactant I and (b) for polymeric surfactant II, respectively.

Table (3) Electrochemical parameters of carbon steel in $0.5 \mathrm{M} \mathrm{HCl}$ devoid of and containing different concentrations of polymeric surfactant I.

\begin{tabular}{ccccccc}
\hline Conc.,ppm & $\boldsymbol{- ~}_{\text {corr }}, \mathbf{m V}$ & $\boldsymbol{\beta}_{\mathbf{a}} \mathbf{m V} / \mathbf{d e c a d e}$ & $-\boldsymbol{\beta}_{\mathbf{c}} \mathbf{m V} / \mathbf{d e c a d e}$ & $\boldsymbol{I}_{\mathbf{c o r r}} \mathbf{m A} \mathbf{\mathbf { c m } ^ { 2 }}$ & $\boldsymbol{\theta}$ & $\boldsymbol{I E \%}$ \\
\hline Free & 520 & 126 & 271 & 0.1810 & & ---- \\
10 & 559 & 108 & 231 & 0.1070 & 0.409 & 40.9 \\
20 & 581 & 99 & 218 & 0.0715 & 0.601 & 60.1 \\
30 & 568 & 94 & 198 & 0.0556 & 0.693 & 69.3 \\
40 & 550 & 87 & 194 & 0.0477 & 0.737 & 73.7 \\
50 & 568 & 91 & 194 & 0.0458 & 0.747 & 74.7 \\
\hline
\end{tabular}


Inhibitive Action of Polymeric Surfactants on the Corrosion of

Table (4) Electrochemical parameters of carbon steel in $0.5 \mathrm{M} \mathrm{HCl} \mathrm{devoid} \mathrm{of} \mathrm{and} \mathrm{containing} \mathrm{different}$ concentrations of polymeric surfactant II.

\begin{tabular}{ccccccc}
\hline Conc.,ppm & $-\boldsymbol{E}_{\text {corr }} \mathbf{m} \mathbf{m V}$ & $\boldsymbol{\beta}_{\mathbf{a}} \mathbf{m V} / \mathbf{d e c a d e}$ & $\boldsymbol{- \boldsymbol { \beta } _ { \mathbf { c } } \mathbf { m V } / \mathbf { d e c a d e }}$ & $\boldsymbol{I}_{\text {corr }} \mathbf{m A} \mathbf{\mathbf { c m } ^ { 2 }}$ & $\boldsymbol{\theta}$ & $\boldsymbol{I E \%}$ \\
\hline Free & 520 & 126 & 271 & 0.1810 & & ----- \\
10 & 559 & 99 & 220 & 0.0712 & 0.607 & 60.7 \\
20 & 555 & 76 & 216 & 0.0465 & 0.743 & 74.3 \\
30 & 550 & 84 & 203 & 0.0436 & 0.759 & 75.9 \\
40 & 555 & 99 & 187 & 0.0419 & 0.769 & 76.9 \\
50 & 555 & 74 & 202 & 0.0319 & 0.824 & 82.4 \\
\hline
\end{tabular}

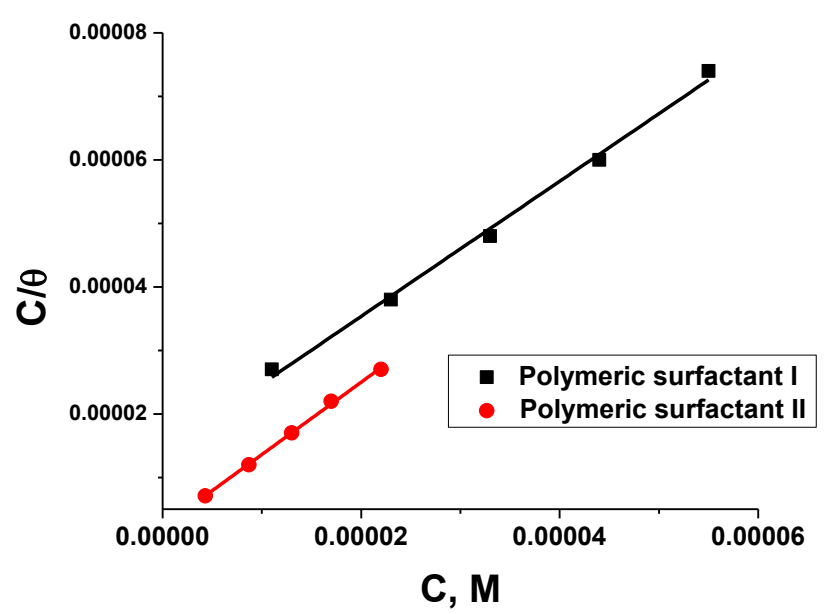

Fig (4) Curve fitting of the corrosion data of carbon steel in 0.5 $\mathrm{M}$ hydrochloric acid solution in the presence of polymeric surfactants at $298 \mathrm{~K}$ to Langmuir adsorption isotherm.

Table (5) The adsorption parameters for adsorption of polymeric surfactant, on carbon steel surface in hydrochloric acid, obtained by applying Langmuir adsorption isotherm.

\begin{tabular}{ccc}
\hline Inhibitor type & $\log \mathbf{K}_{\text {ads }}$ & $\boldsymbol{\Delta G}_{\mathbf{a d s}}^{\circ}(\mathbf{k J} / \mathbf{m o l} . \mathbf{K})$ \\
\hline Surfactant I & 4.85 & -34.50 \\
Surfactant II & 5.65 & -38.66 \\
\hline
\end{tabular}

Table (6) Electrochemical parameters of carbon steel in $0.5 \mathrm{M} \mathrm{HCl}$ containing 50ppm of polymeric surfactant I at different temperatures.

\begin{tabular}{|c|c|c|c|c|c|}
\hline $\mathbf{T},{ }^{\circ} \mathbf{C}$ & $-E_{\text {corr }}, \mathbf{m V}$ & $\beta_{\mathrm{a}} \mathrm{mV} /$ decade & $-\beta_{\mathrm{c}} \mathrm{mV} /$ decade & $I_{\text {corr }} \mathbf{m A} / \mathrm{cm}^{2}$ & IE\% \\
\hline 25 & 071 & 91 & 194 & 0.0458 & 74.7 \\
\hline 30 & 516 & 105 & 226 & 0.0626 & 69.5 \\
\hline 40 & 507 & 100 & 210 & 0.0757 & 67.5 \\
\hline 50 & 017 & 122 & 192 & 0.158 & 59.0 \\
\hline 60 & 507 & 109 & 233 & 0.523 & 50.1 \\
\hline 70 & 507 & 140 & 287 & 1.158 & 47.6 \\
\hline
\end{tabular}



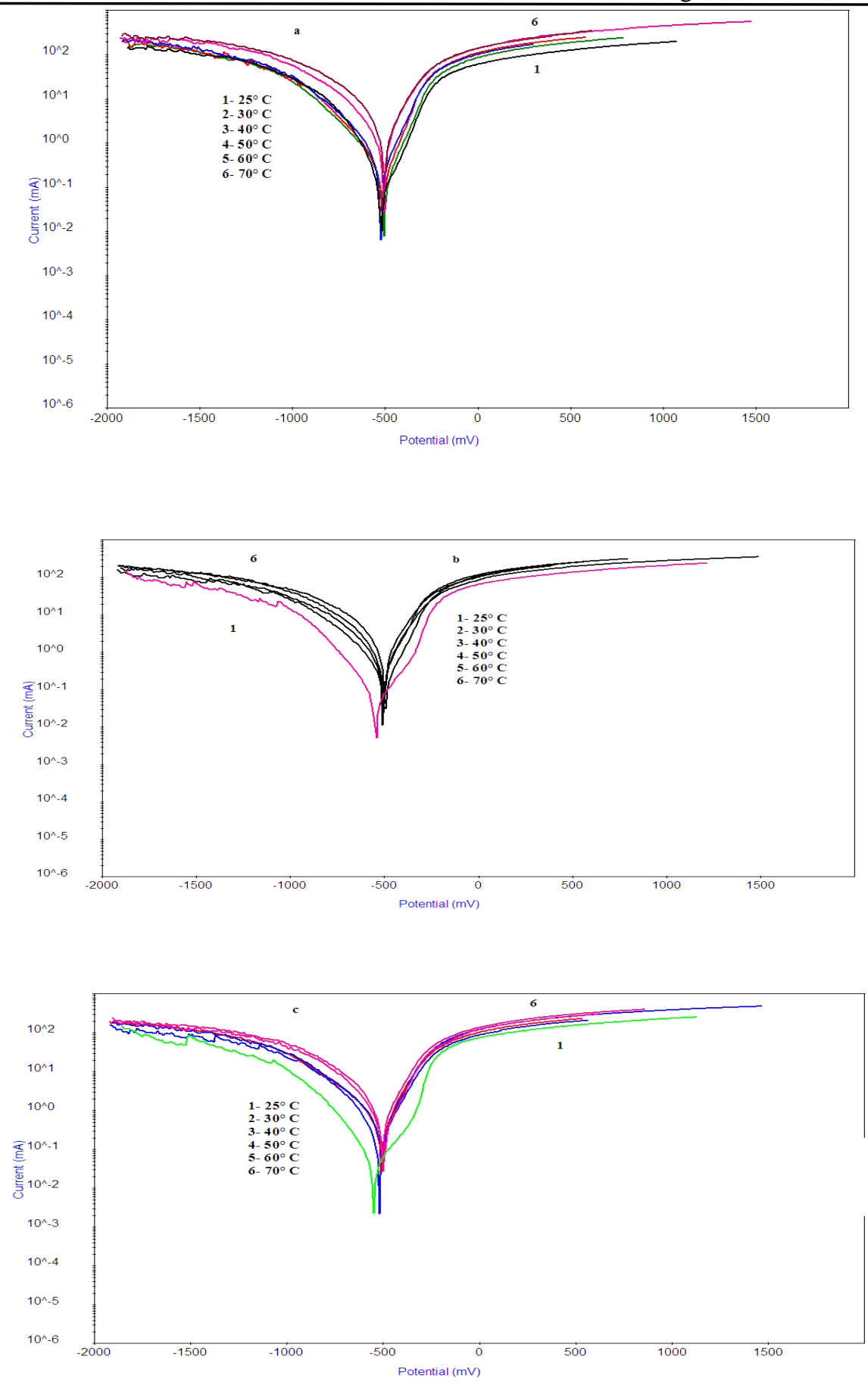

Fig (5) Electrochemical polarization curves for carbon steel in, (a) $0.5 \mathrm{M} \mathrm{HCl}$, (b) $50 \mathrm{ppm}$ of polymeric surfactant I and (c) $50 \mathrm{ppm}$ of polymeric surfactant II at different temperatures, respectively. 
Inhibitive Action of Polymeric Surfactants on the Corrosion of

Table (8) Electrochemical parameters of carbon steel in $0.5 \mathrm{M} \mathrm{HCl}$ containing 50ppm of polymeric surfactant II

\begin{tabular}{lccccc}
\multicolumn{5}{c}{ at different temperatures. } \\
\hline $\mathrm{T},{ }^{\circ} \mathrm{C}$ & $-E_{\text {corr }}, \mathrm{mV}$ & $\beta_{\mathrm{a}} \mathrm{mV} /$ decade & $-\beta_{\mathrm{c}} \mathrm{mV} /$ decade & $I_{\text {corr }} \mathrm{mA} / \mathrm{cm}^{2}$ & $I E \%$ \\
\hline 25 & 555 & 74 & 202 & 0.0319 & 82.4 \\
30 & 564 & 103 & 211 & 0.0582 & 71.6 \\
40 & 524 & 110 & 200 & 0.0681 & 70.8 \\
50 & 516 & 106 & 235 & 0.1180 & 69.8 \\
60 & $0 . \mathrm{r}$ & 111 & 172 & 0.3530 & 66.4 \\
70 & 503 & 117 & 259 & 0.8880 & 59.8 \\
\hline
\end{tabular}

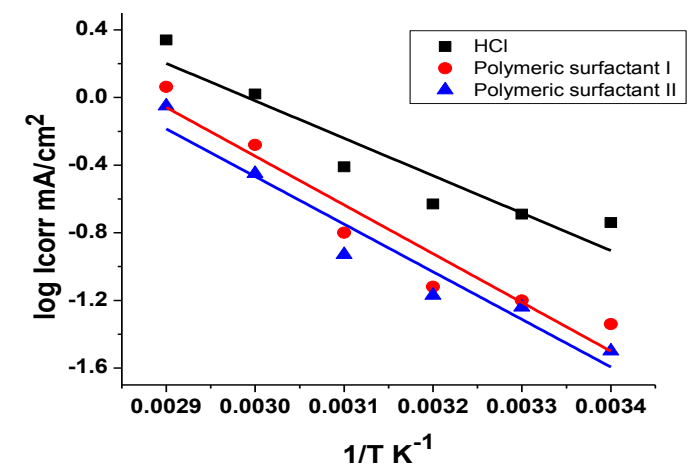

Fig (6) Arrhenius plot for carbon steel in $0.5 \mathrm{M} \mathrm{HCl}$ devoid of and containing specific concentrations of used polymeric surfactants.

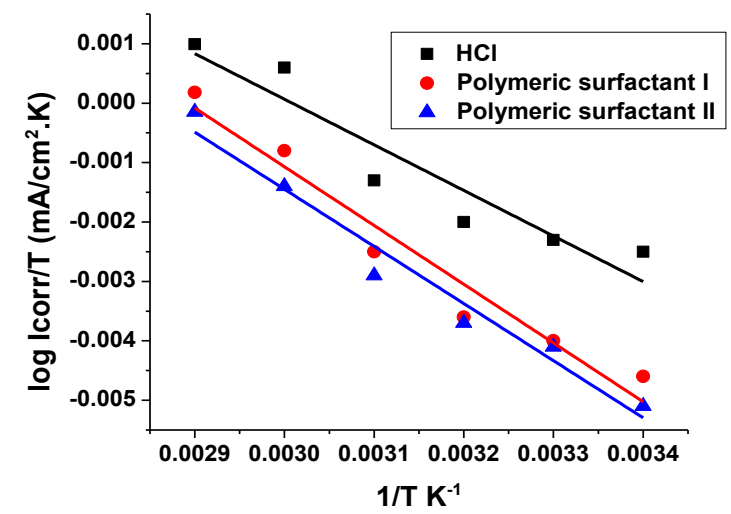

Fig (7) $\log \mathrm{I}_{\text {corr }} / \mathrm{T} \& 1 / \mathrm{T}$ Curves for the corrosion of carbon steel in $0.5 \mathrm{M} \mathrm{HCl}$ devoid of and containing specific concentrations of used polymeric surfactants.

Table (9) Free energy of adsorption and activation parameters of carbon steel in $0.5 \mathrm{M} \mathrm{HCl}$ at specific concentrations of investigated compounds.

\begin{tabular}{lccc}
\hline Inhibitor & $\mathbf{E}_{\mathbf{a}}{ }^{*}, \mathbf{k J} / \mathbf{m o l}$ & $\mathbf{\Delta} \mathbf{H}^{*}, \mathbf{J} / \mathbf{m o l}$ & $\mathbf{\Delta} \mathbf{S}, \mathbf{J} / \mathbf{m o l . K}$ \\
\hline Free acid & 42.39 & 146.89 & -197.12 \\
Polymeric surfactant I & 53.94 & 184.09 & -197.05 \\
Polymeric surfactant II & 55.25 & 189.28 & -197.03 \\
\hline
\end{tabular}

\section{Conclusion}

1- Using weight loss and potentiodynamic polarization measurements shows that used polymeric surfactants acts as good corrosion inhibitors for carbon steel in $0.5 \mathrm{M} \mathrm{HCl}$.
2- The inhibition efficiency of investigated compounds depends on their chemical structure and concentration. 
3- Results obtained from potentiodynamic polarization indicate that the investigated compounds are mixed inhibitors.

4- Inhibition efficiencies increase by an increase in inhibitor concentration and decrease with increasing temperature.

5- Adsorption of these compounds on the carbon steel surface obeys Langmuir adsorption isotherm. The free energy of adsorption reveals physical adsorption.

\section{References}

[1] S.Z.Yao, X.H.Jiang, L.M.Zhou, Y.J.Lv and X.Q.Hu; Materials Chemistry and Physics, vol.104, pp.301-305, 2007.

[2] A.M.Al-Sabagh, M.E.Abdul-Raouf and AbdelRaheem; Colloids and Surfaces A: Physicochemical and Engineering Aspects, vol.251, pp.167-174, 2004.

[3] M.Al-Sabagh, M.A.Migahed and H.S.Awad; Corrosion Science, vol.48, pp.813-828, 2006.

[4] M.A.Migahed, H.M.Mohamed and A.M.AlSabagh; Materials Chemistry and Physics, vol.80, pp.169-175, 2003.

[5] M.A.Migahed, E.M.S.Azzam and A.M.AlSabagh; Materials Chemistry and Physics, vol.85(2), pp.273-279, 2004.

[6] M.A.Migahed, R.O.Aly and A.M. Al-Sabagh; Corrosion Science, vol.46, pp.2503-2516, 2004.

[7] M.A.Migahed, M.Abd-El-Raouf, A.M.Al-Sabagh and H.M.Abd-El-Bary; Electrochimica Acta, vol.50 (24), pp.4683-4689, 2005.

[8] M.A.Migahed, M.Abd-El-Raouf, A.M.AlSabagh and H.M.Abd-El-Bary; Journal of Applied Electrochemistry, vol.36 (4), pp.395-402, 2006.

[9] M.M.Osman, A.M.A.Omar and A.M.Al-Sabagh; Materials Chemistry and Physics, vol.50, pp.271274, 1997.

[10] M.M.Osman, R.A.El-Ghazawy and A.M. AlSabagh; Materials Chemistry and Physics, vol.80, pp.55-62, 2003.

[11] N.A.Negm, A.M.Al-Sabagh, M.A.Migahed, H.M.Abdel Bary and H.M.El-Din; Corrosion Science, vol.52, pp.2122-2132, 2010.
[12] S.A.Abd El-Maksoud; International Journal of Electrochemical Science, vol.3, pp.528-555, 2008.

[13] N.Muthukumar, A.Ilangovan, S.Maruthamuthu, N.Palaniswamy and A.Kimura; Materials Chemistry and Physics, vol.115, pp.444-452, 2009.

[14] M.Z.Elsabee, R.E.Morsi and A.M.Al-Sabagh; Colloids and Surfaces B: Biointerfaces, vol.74, pp.1-16, 2009.

[15] R.F.Godec; Electrochimica Acta, vol.52, pp.4974-4981, 2007.

[16] M.Z.Mohamed, D.A.Ismail, and A.S.Mohamed; J. Surfact. Deterg., vol.8, p.175, 2005. M.Mobin, M.Parveen and M.A.Khan; Portugaliae Electrochimica Acta, vol.29(6), pp.391- 403, 2011.

[17] M.A.Deyab and H.A.Abo Dief, E.A.Eissa and A.R.Taman; Electrochim. Acta, vol.52, pp.81058110, 2007.

[18] Y.Tang, X.Yang, W.Yang, R.Wan, Yizhong and X.Yin; Corrosion Science, vol.52, pp.1801-1808, 2010.

[19] M.Dacres, R.A.Sutula, and B.F.Larrick; J. Electrochem. Soc., vol.130, p.981, 1983.

[20] A.A. El-shafei, M.N.H. Moussa and A.A.El-far; J. Applied Electrochemistry, vol.27, p.1075, 1997.

[21] M.A.Quraishi and F.A.Ansari; J. Applied Electrochemistry, vol.33, pp.233-238, 2003.

[22] M.Lebrini, F.Bentiss and H.Lagrenee; Corrosion Science, vol.48, p.1279, 2006.

[23] M.Ehteshamzadeh, T.Shahrabi and M.Hosseini; Anti. Corros. Methods Mater., vol.53, pp.296302, 2006.

[24] F.Bentiss, M.Lebrini and M.Lagrenee; Corrosion Science, vol.47, pp.2915-2931, 2005.

[25] N.M.Guan, L.Xueming and L.Fei; Materials Chemistry and Physics, vol.86, pp.59-68, 2004.

[26] A.S.Fouda, A.A.Al-Sarawy and E.E.ElKatori; Desalination, vol.201, pp.1-13, 2006. 